\title{
How startups utilize organizational adaptability in digital innovation
}

\author{
Dulce Goncalves \\ Halmstad University, Sweden \\ dulce.goncalves@hh.se
}

\author{
Magnus Bergquist \\ Halmstad University, Sweden \\ magnus.bergquist@hh.se
}

\begin{abstract}
In a global digital market, startups must have the capability to handle apprehension of knowledge and utilization of knowledge efficiently to quickly adapt to new realities as these emerge, given their limited resources-this regardless of whether it is customer needs or other events that affect the market. However, we do not know how startups quickly change course and adapt to stay competitive in the market. Therefore, we conducted a qualitative study based on 23 interviews with nine globally active automotive startups to understand startups' fast adaptability and how it impacts their digital innovation capability. The results show that startups with an organizational agility capability efficiently handle the transition between all four stages of innovative thinking. We conclude that dealing simultaneously with a problem from several different perspectives accelerates the apprehension of knowledge through concrete experience and abstract thinking; experimenting with new solutions develops new insights and knowledge. Keywords: Organizational Agility, Organizational Adaptability, Framework for Creative Problem-Solving Styles, Digital Innovation, Startups
\end{abstract}

\section{Introduction}

Digitalization has significantly challenged many industries, particularly the automotive industry [1]. Digitalization has forced incumbent automotive companies to reconsider the car and view it as a mobile multi-faceted platform for continuous digital service delivery. They, as organizations, are actors in an ecosystem [2, 3, 4, 5]. Applying new digital technology in a routinized technological regime, e.g., automotive incumbents prevents them from applying the potential of digital technology and leads to the expected differentiation strategy for the automotive incumbent's new products not being achieved [6]. Many automotive incumbents continue to sell innovations, such as electric cars, similar to the past, meaning selling a fixed product that can be 'configured' to a certain degree but not upgraded afterward. As a result, it may not be possible to purchase additional functions afterward due to incompatibility with the current platform.

In contrast to seeing the product as a finished stock product with several features and packaging, newer tech companies, e.g., Tesla, offer electric cars as a mobile platform enabling driving experience for today and for the future to come. The customer chooses what level of future experience they are willing to pay in advance, basic or advanced driving experience. The car is seen as a mobile platform continuously renewed with innovative solutions, not just bug fixes and efficiency improvements [1]. Although some car manufacturers may offer car-as-a-service, which means not owning a car, the companies' value proposition and business models seem unchanged.

For product companies to thrive in a continuously changing market, they may be required to transform their thinking and craft a capability to continuously adapt to market changes, namely, organizational agility $[2,7]$. Except for quickly embracing and adopting new technologies to constantly keep up with accurate technical competence $[8,9]$, companies may also change from vertical to horizontal leadership and strive to keep the organizational structure as lean as possible. Fostering an agile innovation culture can facilitate continuous learning leading to new knowledge that can give the company an advantage in innovation [6]. Such 
agile behavior and values seem to be something startups have been able to master better than incumbents $[8,9,10]$.

It is well known that startups have a capability for rapid adaptability in fast and continuously changing markets. However, not much is known about how they achieve this capability. It enables organizational agility and how it affects their ability to innovate. To better understand how startups' adaptability enables organizational agility and affects their ability to innovate, we have chosen to conduct a qualitative study that can shed light on and answer the following research question: How do startups use organizational adaptability in digital innovation?

The paper is organized in the following way: first, we review previous research on organizational agility and relate that to research on the relationships between organizational adaptability and digital innovation. After that, the method section presents the qualitative study and selection of companies, followed by results and analysis. The result and analysis are then discussed from an organizational adaptability perspective to show how adaptability can strengthen companies' organizational agility and digital innovation capability. The paper ends with conclusions, limitations, and future research.

\section{Background}

Organizational agility is rooted in two related concepts-organizational adaptability and organizational flexibility [10]. We define organizational agility as the capability of a company to rapidly change or adapt in response to changes in the market. Organizational adaptability can be defined as an ability to master the process of deliberately changing routines [11].

\subsection{Organizational agility}

Organizational agility is defined as an organizational capability to adapt to continuously unpredictable market changes $[13,14,15,16]$. Although agility has been discussed since 1991 as an agile enterprise concept primarily for manufacturing [12], when practitioners in 2001 presented the agile manifesto within software product development, agility gained some interest among researchers and practitioners. Agility is culture-driven and not processdriven; promoting a change culture is vital to successfully achieving organizational agility and developing continuous digital innovation capability [17]. Furthermore, to succeed in scaling agile to an enterprise level, new approaches to leadership and management might be needed [18]. The main driving force for agility is change and innovation [18, 19, 20]. Companies usually require entrepreneurial leadership and talents to succeed with fast adaptability to change, all of which will facilitate an ability to sense, seize, and transform to capture new business opportunities as they arise [19, 20].

\subsection{Organizational adaptability}

Organizational adaptability is primarily a proactive process enabling organizations to intentionally and continuously change and create [11]. Organizational abilities such as curiosity and creativity enable proactively experimenting with new technology and methods for solving new challenges, leading to new insights, knowledge, and solutions long before competitors [11]. However, developing organizational adaptability may require new ways of leading organizations to thrive in an increasingly complex, uncertain volatile market [21]. Mastering incremental changes is no longer sufficient since the threats and opportunities converge and influence each other and create unique situations [21]. For organizations to handle complexity, there needs to be an operational ability to align systems and processes for efficiently executing ideas to productive outcomes, e.g., exploitation [21]. Exploration relies on organizations to develop an ability to continuously and intentionally scan the market to anticipate new problems to solve and proactively find new ideas for innovative solutions to implement that ultimately can give them a competitive advantage [22]. Creativity is primarily a collective process that facilitates that different perspectives accelerate new insights that can lead to innovative solutions to new challenges [10, 22, 23]. Effective innovation requires knowledge and experience coverage for the whole innovation process from ideation to implementation $[22,23]$. According to Uhl-Bien and Arena [21], organizations do not seem to have a shortage of new ideas, but rather a challenge to capture these ideas and engage in networked dialogues to develop, test, evaluate, and refine ideas for innovation growth. To better succeed with organizational adaptability, the organization needs to 
transform into a thinking organization, meaning crafting an organizational capability of both unlearn and invent [22]. Adaptability and flexibility are inextricably linked to organizational agility and depend on innovative thinking [22]. Becoming a thinking organization needs to understand the importance of all four stages of the innovation process (Figure 1). Innovation cannot be out-commanded by management or be turned on and off.

Organizations should make innovative thinking a routine that can develop an innovation culture over time, enabling a fast response to change and developing better solutions continuously [10, 22]. Furthermore, organizations need to overcome the shortcomings in thinking skills that may negatively affect individuals and teams, leading to uncreative teamwork. According to Basadur [22], both research and practical experience indicate that critical thinking skills are vital to executing innovation. As an example, Basadur [22: p57] states, "Some organizations publicly display slogans such as 'Innovation is our most important goal' but when asked 'what are you doing about it?' their top managers reply, 'why, nothing.'" Lack of psychological safety [24] means that both teams and managers have to overcome their fear of losing control or not being accepted for their ideas and recommendations on solving problems unless they can prove it with data [22].
Senior management needs to lead by example, which requires leadership transparency, and that they also need to learn how to craft a culture that continuously can respond to change and engage the rest of the organization in daily applying a kind of thinking and behavior that ultimately can enable continuous innovation at a high pace $[10,22]$. If everyone within an organization feels safe to reflect and share their thoughts, insights, worries, and creative ideas to solve challenges without hesitation, it can accelerate innovation. Applying a sounding board to work through complex challenges where everyone questions and contributes with different angles to the challenges and suggests the way forward can facilitate abstract thinking and continuous learning. When people feel that they actually can make a difference, they will commit to their best ability.

It seems that when organizations struggle to become successful, they usually lack clarity regarding at least one of the following components: understanding the business need, infrastructure, or having a creative culture and process in place [10, 22]. However, agile organizations seem to generate new ways of thinking and operating, supporting new ideas flow into the operational system generating innovation and adaptive outcomes [21]. Figure 1. The four stages of the innovative thinking and the two dimensions of the
innovation process: apprehension and knowledge utilization $[11,22]$.

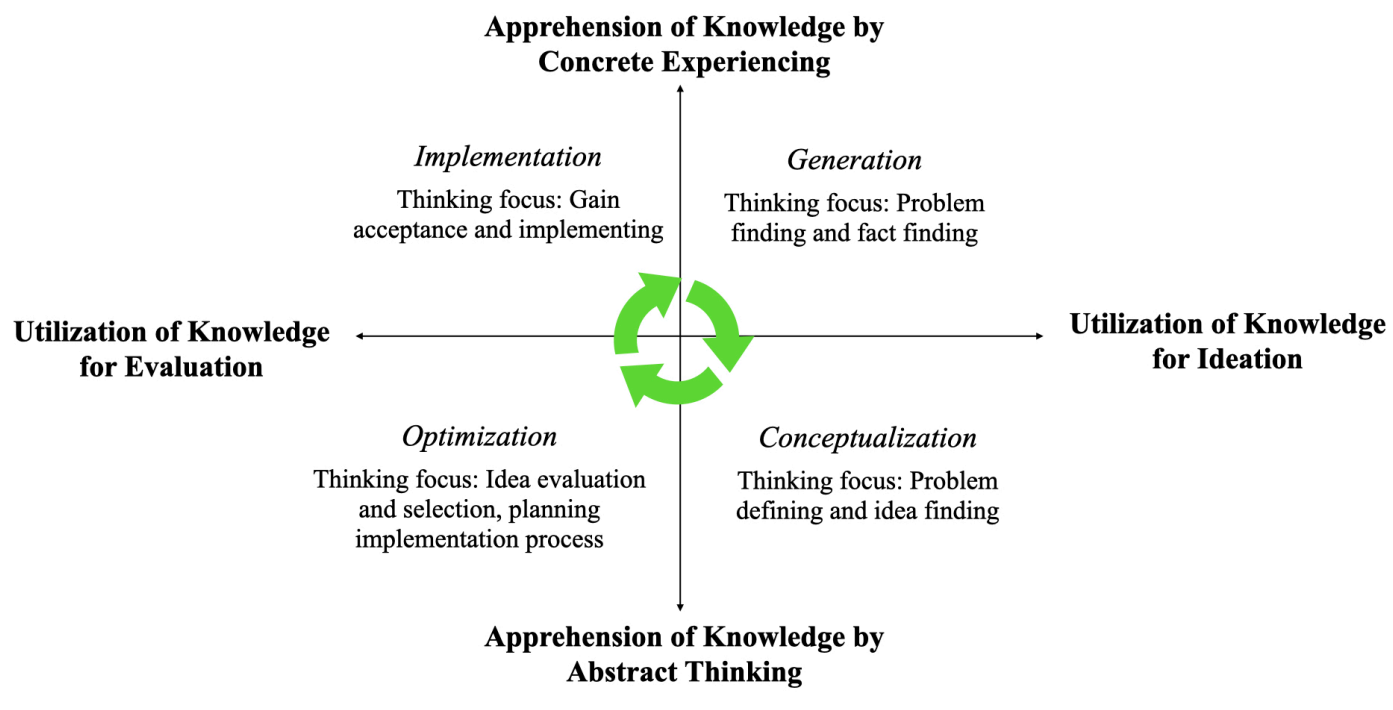




\subsection{Analytical lens}

To facilitate our analysis of how startups adapt when they innovate, we have chosen to be inspired by a framework for creative problem-solving styles, based on four phases of innovative thinking and two dimensions of the innovation process: apprehension and knowledge utilization (see Figure 1) [11, 22]. There are two dimensions to this framework. The first dimension represents apprehension of knowledge, experiencing vs. thinking. The experience could be described as learning by doing, physical processing, which is different from thinking, where knowledge is gained through independent, abstract thinking or mental processing. The second dimension represents how knowledge is utilized if applied for ideation, creating new options, or evaluating options. When knowledge is applied for ideation, it is nonjudgmental, creating new information to increase various options. In contrast, knowledge applied for evaluation is judgmental since decisions about new information are reached by reducing various options. Organizations and people apply their knowledge both ways for both dimensions, but the relative ratios might differ from others.

\section{Method}

\subsection{Research approach}

To answer the research question on how startups use organizational adaptability in digital innovation, we chose a qualitative multi-case method where one company corresponds to one case [25]. Semi-structured qualitative interviews were conducted, enabling interviewees to exemplify how they handled organizational adaptability [26]. The qualitative method facilitates a more in-depth understanding of peoples thinking and behavior in terms of the norms, values, and culture in their organization, as we continuously learn during our dialogue [26].

\subsection{Data collection}

Nine international automotive startups were selected based on the following selection criteria: the startup is no more than ten years old, the founder is still in the company, and the startup should have a headcount of at least four employees (Table 1). The startup should be a product development company, and digitalization is part of their core business. The startup size in Table 1 follows the European Commission definition of SMEs ${ }^{1}$ being companies that meet a certain employee headcount. The startups were mainly in Sweden and one with its mother company in the

Table 1. Selection of key informants for this study

\begin{tabular}{|c|c|c|c|c|}
\hline Startup & Size & Type & $\begin{array}{c}\text { People } \\
\text { Interviewed }\end{array}$ & Roles Interviewed \\
\hline A & $\mathrm{S}$ & Incubator: Internet of Things \& AI & 4 & $\begin{array}{l}\text { Co-Founder; CEO; Head Sales; SW Team Lead; } \\
\text { Company Board Member Ext Invest }\end{array}$ \\
\hline B & S & $\begin{array}{l}\text { Incubator: Digital services \& HW } \\
\text { product }\end{array}$ & 2 & Co-Founder; CEO; Partner; Product Owner \\
\hline $\mathrm{C}$ & $\mathrm{S}$ & Digital services & 4 & Co-Founder; CEO; CTO; CCO; UX/Dev. \\
\hline $\mathrm{D}$ & $\mathrm{S}$ & Two-sided consumer platform & 2 & CEO; Keyless Lead \\
\hline $\mathrm{E}$ & M & $\begin{array}{l}\text { OEM, electric vehicle \& new } \\
\text { platform }\end{array}$ & 5 & $\begin{array}{l}\text { Marketing Director; Autonomous System Director; } \\
\text { Innovation Manager; Head of Software; Director } \\
\text { Energy Storage }\end{array}$ \\
\hline $\mathrm{F}$ & M & Two-sided consumer platform & 1 & Director R\&D \\
\hline G & $\mathrm{S}$ & $\begin{array}{l}\text { Incubator: Digital services, } \\
\text { consulting }\end{array}$ & 1 & CEO \& Co-Founder \\
\hline $\mathrm{H}$ & S & Incubator: HW \& SW platform & 3 & Co-Founder; CEO; Board Member; Developer \\
\hline I & M & $\begin{array}{l}\text { SW for self-driving cars and } \\
\text { autonomous mobile robots }\end{array}$ & 1 & Co-Founder; CEO \\
\hline
\end{tabular}

\footnotetext{
${ }^{1}$ https:/ec.europa.eu/growth/smes/sme-definition_en
} 
Netherlands and one in the USA but active in Sweden. The startups were chosen for their active approach to digital service innovation and their ambition to master the new digital service market. This force is generally driving innovation in the automotive domain today [27]. Four out of nine startups were or had been connected to a corporate incubator to speed up their cocreation capability with incumbents [28].

A semi-structured interview guide was designed, including 37 predefined open-ended questions and 11 questions to cover demographics. Primarily founders and strategic management positions were interviewed to better understand the company's board and top management enabled organizational adaptability facilitating co-creation to promote digital innovation growth. In addition, other organizational actors were interviewed to provide a broader view and verify whether the management statements could be correct [29]. To support us in answering the research question on how startups use organizational adaptability in digital innovation, we conducted 23 interviews. Each interview had a duration of approximately $2 \mathrm{hrs}$. All interviews were recorded and afterward transcribed. Additional secondary data have been collected, including web pages, white papers, social media, and a literature review [29]. Secondary data has primarily been used to strengthen our argumentation in the introduction section and sometimes also to verify the interviewer's statements.

\subsection{Data analysis approach}

A systematic combining approach was applied, moving back and forth between data, preserved literature, frameworks, and analysis [30]. The data analysis was performed by transcribing and coding the recorded interviews using a bottom-up method [31]. We then compared each recorded answer with the corresponding application area for interview questions to systematically identify similarities and differences in how the startups applied organizational adaptability in their digital innovation [26]. We have applied our analytical lens to see how the startups' gained and applied their knowledge for their innovation initiatives. To further strengthen our results and reasoning, we have chosen quotes from our interviews to give a sense of how these companies think about their business, market opportunities and how they learn and apply their knowledge to strengthen their digital innovation.

\section{Results}

After an initial description of the companies' efforts with digital innovation, adaptability is presented organized based on the four stages by describing how the startups worked in the four different stages of innovative thinking and how they gained and applied their knowledge.

For the startups to succeed innovatively, the companies created conditions for the innovation process to happen. The most critical conditions that the companies raised were, among other things, to recruit towards the corporate culture. Not all individuals, regardless of how great they are, function in an innovative environment, according to the major part of the startups. All companies mentioned how vital it was to recruit the right talent. The startups stated that they were very restrictive about whom they recruited; given how vulnerable they were, an individual who does not fit in can become an impediment by creating an environment that silences its colleagues from sharing their ideas, knowledge, and experience, stalls collaborations, which in turn causes innovation not to happen. "The people that are hired have the right attitude and fit for this company. It is more important than that have the right experience."-Startup E. "I want to hire who is most eager to learn the most in this area. And who is interested to show that he wants to learn rather than that he knows everything." - Startup H. Some companies emphasized how important it was to have a high level of transparency so that all employees would feel safe and included, that they were part of a "family" company, that everyone's ideas count. For this to happen, it was essential to create a work environment where individuals feel safe in sharing new ideas and are not questioned.

Co-founder of Start B mentioned that he missioned so that people would understand the difference between respecting each other but not being afraid to question an idea they did not understand or did not agree on, "Respect for the person, not the ideas." An interesting comment was from one of the founders of startup C. Before founding the company, he had applied for a job at a market-leading electric car company in Silicon Valley but chose to interrupt the recruitment process because the company did not provide work-life balance. The company was transparent that they only want to work with the best. As long as the employee performs, the company 
supports the employee- "HR explained that every week on Friday, you would receive an email if you are welcome back on Monday. They just want to work with A-players. They can bring in B-players if they can expect you to become A-player. If you do not step up and deliver, you will be voted out and have to leave the company. They do not want to continue educating people. They do not want to slow down their development due to others not being able to perform."

\subsection{Knowledge generation}

The most effective innovation startups had a lean innovation process to secure that all their peoples' ideas would be captured and considered. Startup E explained that they had a lean system to identify ideas within the company, a lean structure, meaning a simplified structure, for how they deal and filter the ideas, and a feedback loop to Market and R\&D for verification if the idea still would be an opportunity or if there would be solutions already provided by other competitors out on the market. All employees can submit new ideas to the company's 'idea box'. The ideas are afterward filtered by their innovation director, who sends the ideas to the market department for verification if there is any business opportunity and if there are already solutions available on the market. Suppose there is a business opportunity and no solution is available on the market; the idea is passed to R\&D for verification if it is feasible to develop. If the patent committee approves the new idea, it gets patented. The innovation directors follow up with finance to verify that the company can afford to build the new idea. Even though a lean structure facilitated ideas to be captured and opportunities not to be lost, another individual at the company stated, "We do not have a type of structure. It is the chaos that feeds creativeness. That is the whole point of being a startup." The term structure seemed to be tagged to preconceived ideas based on whom we spoke to and based on the individual's previous work experience. Some other startups described that it is crucial to get the customer constraints to succeed with innovation. It was essential to keep a brought idea capturing, including both internal and external ideas. Innovation needs to solve real problems, and one way to master this challenge was to keep a tight sales dialogue with customers to capture the problems they needed support with to resolve in a good way. However, for innovation to solve real problems, startups stated that they tried to apply open innovation to better understand the context and problem from a broader customer perspective. The co-founder and CEO for startup A explained that it was vital that everyone within the company understood the customer problem. By incorporate and be transparent with its people in the sales activities, it enabled commitment and engagement. "Conversely, employees are our most important customer representatives. We cannot only have sellers, but the whole delivery part must be the sellers are in and working on the project. When the next project starts, then they have to know what we do and why."-Startup A. Other channels for idea capturing were social media where some of the startups kept their customer dialogue asking customers for feedback or providing ideas that would give them added value if the company could provide solutions that would resolve the problems. It was not always the volume of requirements that were most important for startups. However, the most important thing was to secure the requirements and needs of a broader target group from different domains to ensure that the startup did not design an overly narrow product that would not work for the broad customer group. In addition, it was a way to mitigate the risk that the company did not build itself into a corner and later would not be able to adapt the product to new markets or customer groups quickly. Therefore, they wanted to build flexibility into the product from the very beginning. "I do not think we need so much more global input, rather more different actors to give us the input."-Startup C

\subsection{Knowledge conceptualization}

For an idea to be selected, it needed to resolve a real customer problem that not already would have been resolved by another market competitor. "One may not have to have a great idea, but one must at least have a business-working idea and then work hard towards it or find a constellation of working towards it."-Startup C. The conceptualization phase was where startups simultaneously spent a substation part of their time working on value propositions to figure out what business model to apply for a particular value proposition. "We only work with requirements from our letter of intent customers. We only work with business model innovation and strategy with our partners on who should buy the things. We have not made many decisions internal, but we have often gone out and 
asked. At the same time as when we have received the answers, we have sat and modulated it for hours internally." - Startup C. The startups kept an open mind for different simultaneous concepts since their product might change during its product lifecycle. "Suppose we have a market platform or a license; the licensed product will go to another who has a market product. However, at the same time, it is an end consumer who will see that product. It will, for example, be a percentage under a motorcycle or similar. So if we build a platform, it is guaranteed to be an end-consumer product, even if large companies also trade on that platform. Nevertheless, until then, we only work B2B with our partners." - Startup C.

\subsection{Knowledge optimization}

The startups handled optimization for their products differently due to applying different innovation concepts. For example, some startups applied a Lean Startup model to reach out to their customers via social media or measure how fast and often customers used the product. Others applied co-creation in the ecosystem by viewing its product in the center and simultaneously testing it towards the different customer domains, enabling fast optimization. "We will develop a product that will be a spider in the middle of a net which customer would involve around. If we succeed, we will benefit from a service to an ecosystem between different companies. We need to understand exactly what all companies need, requirements and needs, and their business models. Furthermore, we need to adapt to everyone simultaneously so we cannot just adapt to one customer at a time because then we would end up in a lock-in situation. We must have great flexibility."-Startup C. Value chain modeling was something some of the startups tried to apply to be able to capture where their product would add the most value for customers and the company. Startups working towards municipalities tended to apply experimentation pilots together with its customer and fine-tune the product more or less in real-time to fast find the best optimization for a particular customer context.

\subsection{Knowledge implementation}

When it came to implementation, it could be split into two phases. The first phase is when the companies implemented the first embryo prototype needed to test and receive the first feedback loop from real customers, meaning no dry-run. After the first iteration, most startups applied a Scrumish development approach, meaning an iterative, incremental development approach with customers in the loop and adjusting until achieving wanted value for both customer and company. In addition, it is an effective innovation approach that enables startups to remain in control over their financial situation and adjust when needed and fast respond to required changes by customers or the market. Some startups even applied co-development by coding in the customer's product for integration and coding in the startup's product. The method enables the speed of innovation because it improves the apprehension of knowledge for both concrete experiencing and abstract thinking in its proper context and facilitates the development of a trustworthy relationship with its key customers. Building a trustworthy relationship with key customers is vital for co-creation to happen. However, everyone complained that the intended co-creation with the incumbents had never happened for startups connected to the incubator. Once they had established a connection at the incumbent, the contact person had vanished. Thus, the planned co-creation activities never started, and the startups were left to their fate. These startups stated that they had to accept and adapt to the circumstances. Nevertheless, being connected to the incubator had a marketing value and facilitated the startups to grow their business network.

\section{Discussion}

Organizational agility has become imperative for companies to remain competitive in an increasingly rapidly changing digital market. It enables companies to become proactive and fast sense, seize and adapt to new realities [5]. As many of the startups pointed out, to succeed with innovation, it is vital to get the right talents to join the company, meaning people who match the company culture [10]. For startups, innovation primarily revolves around different forms of open innovation with external actors, mostly other startups or municipalities, public sector [7]. Therefore, collaboration skills are essential. People need to master how to quickly develop trustworthy relationships with external actors to get innovation to occur [32].

Knowledge generation: Companies can get far with a lean structure for idea capturing to secure that 
new ideas from all their employees that could contribute to new opportunities are not lost. When it came to knowledge generation, the major part of the startups applied full transparency towards all their employees regarding their customer dialogues enabling a deeper understanding of the customer problem in its proper context. For startups, knowledge sharing is vital due to their resource limitation. There is a need for the startups to utilize the company's available knowledge as efficiently as possible. Furthermore, transparency enables trustworthy relationships with customers, making customers more open to being transparent with their current challenges. The more accurate the information regarding the actual problem, the higher the probability of focusing on solving the most valued customer problem.

Based on the fact that a lean structure for capturing ideas seems to be sufficient, as long as people are willing to share their ideas and knowledge with others, we propose that (P1): Lean structure for idea capturing ensures that an organization does not miss out on any idea from their employees that could lead to a new business opportunity. For enabling idea and knowledge sharing to happen, we propose (P2): Transparency builds trust, leading to trustworthy relationships and commitment with all involved innovation actors, enabling ideas and knowledge exchange to occur.

Knowledge conceptualization: To keep up with this fast innovation pace, startups will need to retain an open mindset and safeguard their ability to continue transforming their thinking whenever needed [2]. New ideas need to resolve real customer problems increase the probability of generating revenue for the company. Constantly transforming the thought will probably be the most difficult to maintain. We can already see this on the market when, e.g., car companies are trying to compete with Tesla. All premium brands are trying to quickly develop electric cars that compete with Tesla in terms of range. However, their technology regime becomes an impediment to enable acceptance for new ideas to be conceptualized [6]. They have not transformed their thinking but have continued to think of the car as a stock product and not as a connected software platform that continuously gets renewed with new services and often has no additional cost. Furthermore, key customers might not be the same as in the past. They might now be located within a new domain.
Based on a need to build a capability for continuously transforming the way of thinking to enable innovation at a high pace, we propose (P3): Apprehension of knowledge through abstract thinking forces employees to understand what other actors with different backgrounds mean by their point of view. When this gained knowledge also is experienced through concrete experience, it enables thinking transformation to occur. Therefore, we propose (P4): Companies that integrate continuous learning into their daily work maintain rapid adaptability and flexibility through continuously thinking transformation ability.

Knowledge optimization: Different innovation concepts could facilitate knowledge optimization, e.g., the lean startup concept [33] or co-creation in an ecosystem. Applying a broad customer requirement capturing with fast concept evaluation feedback loops mitigates getting the startup in a lock-in situation. Value chain modeling is essential to secure that the startup can provide the most added value for its customers and the company. It is a way to fine-tune the product concept along the innovation product lifecycle efficiently.

Based on the fact that a broad perspective on different customer domain need could support organizations optimize their product for a broader customer base mitigating the organization getting into a lock-in situation. We propose (P5): Simultaneously dealing with a problem from several different perspectives accelerates knowledge apprehension through concrete experience, leading to new insights emerging while experimenting to find a solution that can solve the problem.

Knowledge implementation: A gile implementation practices can support startups to maintain control over their innovation progress, financial situation, and acceptance of the solutions evolving after each sprint effectively. Suppose they, e.g., apply the Scrum framework [34] and utilize crossdisciplinary teams following the Scrum ceremonies and usage of an agile toolbox, like the product and sprint burn-downs. In that case, they will fast see when the gap between their available means and what is remaining work is growing and highlight when reprioritization of ongoing product innovation is needed and fast adapt to optimize for the most value to customer and company. A sprint can be mitigation for affordable loss [35], which the sprint duration can mitigate. The more insecure or narrow means, the 
shorter the sprint should be and minimize the company's affordable loss. The daily stand-up gives the team a chance to reflect on how their ongoing work progresses, any impediments, risks, or knowledge gaps they need support with, and any replanning is needed to secure their deliverable of the committed goals. At the end of the sprint, the sprint retrospective contributes to continuous learning by reflecting on the team members' insights, challenges, and if anything needs to be dealt with on the upcoming sprint to prevent a more significant negative impact [23]. At the end of the sprint, the Sprint demonstration will capture product feedback loops from stakeholders and knowledge sharing, contributing to continuously learning about the ongoing product innovation progress $[23,34]$. The ongoing insights from this innovation progress can enable stakeholders to make the needed adjustments to enable the new product launch or the integration into the customer environment. Since the information is typically open to everyone within the company, and some companies even keep the information open for their external actors such as key customers for the particular innovation initiative, this openness enables rich transparency, leading to a trustworthy relationship [32]. Keeping information open can get the key customers committed to supporting the teams by answering questions and opening doors towards new target groups within and outside the customer organization. An approach that could lead to getting the customers as ambassadors for the companies innovation towards other potential customers. The approach can contribute to accelerating the innovation pace and market launch.

Based on that, agile implementation practices seem to support organizations to handle continuous innovation at a high pace in a controlled way. We propose the following (P6): Agile organizations that efficiently handle the transition between all four stages of innovative thinking are supported by an agile organizational culture.

\section{Conclusions}

This paper aimed to clarify how startups use organizational adaptability in digital innovation. First, we conclude that agile organizations, meaning flexible and adaptable, can efficiently handle the transition between all four stages of innovative thinking. Second, startups that promote an agile culture, which means collaboration across company boundaries, make it easier to move knowledge from the inside out and vice versa, retain growing knowledge for the company and enable rapid adaptation to new opportunities. Third, when simultaneously dealing with a problem from several different perspectives, it accelerates the apprehension of knowledge through concrete experience. At the same time, as experimenting with finding a solution that would solve the problem, new insights will emerge. Fourth, when it comes to apprehension through abstract thinking, it forces talents to understand what other actors with different backgrounds mean by their point of view. Finally, for companies to maintain rapid adaptability and flexibility, and organizational agility, they should consider integrating continuous learning into their daily work. At present, this might not be vital since these knowledge gaps are handled with contributions from external actors.

\section{Limitations and Future Research}

A clear insight from this study is the importance of mastering collaborations with external actors to facilitate access to the needed knowledge that startups do not have but need to keep up with continuous digital innovation at a high pace, particularly for co-creation in ecosystems and communities. An agile culture seems to be an essential enabler for collaboration with external actors for co-creation.

The small sample of automotive startups may affect the generalizability. However, we believe that similar procedures may also apply to startups in other domains of digital innovation initiatives. We, therefore, provide six propositions in the discussion section to be tested in future research. Testing the propositions may increase the generalization and transferability of the results to other domains.

\section{References}

[1] I. Sebastian, J. Ross, C. Beath, M. Mocker, K. Moloney, and N. Fonstad, "How big old companies navigate digital transformation", MIS Quarterly Executive, 16, 3, 2017, pp. 197-213.

[2] M.W. Van Alstyne, G.G. Parker, and AP Choudary, "6 Reasons platforms fail", Harvard Business Review, March, 2016.

[3] U. Eliasson, R. Heldal, J. Lantz, and C. Berger, "Agile Model-Driven Engineering in Mechatronic Systems - An Industrial Case Study", In conference proceedings The 
International Conference on Model driven Engineering Languages and Systems, 2014, pp. 433-449.

[4] M. Swan, "Connected Car: Quantified Self becomes Quantified Car", Journal of Sensor and Actuator Networks 4, 2015, pp. 2-29.

[5] C. Burchardt and B. Maisch, "Digitalization needs a cultural change - examples of applying Agility and Open Innovation to drive the digital transformation", Procedia CIRP 84, 2019, pp. 112-117.

[6] DB Audretsch, "Technological Regimes, Industrial Demography and the Evolution of Industrial Structures." Industrial and Corporate Change, 6, 1, 1997, pp. 49-82.

[7] D. Goncalves, M. Bergquist, R. Bunk, and S. Alänge, "How co-creation supports digital innovation in Automotive startups", In conferencing proceedings Twenty-Ninth European Conference on Information Systems (ECIS 2021), Marrakesh, Morocco.

[8] B. Jovanoci, "New Technology and The Small Firm", Small Business Economics 16, 2001, pp. 53-55.

[9] Z.J. Acs, A. Song, L. Szerb, D.B. Audretsch, E. Komlosi, "The Evolution of the Global Digital Platform Economy", 2021, pp. 1971-2021." Available at SSRN: https://ssrn.com/ abstract $=3785411$ or $\mathrm{http}: / / \mathrm{dx}$.doi.org/10.2139/ssrn.3785411

[10] D. Goncalves, M. Bergquist, R. Bunk, and S. Alänge, "Cultural aspects of organizational agility affecting digital innovation", Journal of Entrepreneurship, Management and Innovation, 16, 4, 2020, pp. 13-46.

[11] M. Basadur, G.Gelade, and T. Basadur, "Creative Problem-Solving Process Styles, Cognitive Work Demands, and Organizational Adaptability", Journal of Applied Behavioral Science, 50, 1, SAGE, 2014, pp. 80-115.

[12] SL. Goldman, N. Roger, and K. Preiss, "Agile Competitors and Virtual Organizations", Van Nostrand Reinhold, New York, 1995.

[13] R. Dove, "Response ability: the language, structure, and culture of the agile enterprise." John Wiley \& Sons, New York, 2001.

[14] V. Sambamurthy, A. Bharadwaj, and V. Grover,"Shaping Agility Through Digital Options: Reconceptualizing The Role of Information Technology in Contemporary Firms", MIS Quarterly 27, 2, 2003, pp. 237-263.

[15] P.P. Tallon and A. Pinsonneault, "Competing perspectives on the link between strategic information technology alignment and organizational agility: insights from a mediation model", MIS Quarterly, 35, 2, 2011, pp. 463-486.

[16] D. Teece, M. Peteraf, and S. Leih, "Dynamic Capabilities and Organizational Agility: Risk, Uncertainty and Entrepreneurial Management in the Innovation Economy", California Management Review, 58, 4, 2016, pp. 13-35.

[17] M. Brettel, R. Mauer, A. Engelen, and D. Küpper, "Corporate effectuation: Entrepreneurial action and its impact on R\&D project performance", Journal of Business Venturing, 27, 2, 2012, pp. 167-184.

[18] L. Holbeche, "The agile organization: How to build an engaged innovative and resilient business", Kogan Page, London, 2018.
[19] K. Conboy, "Agility from first principles: Reconstructing the concept of agility in information systems development", Information Systems Research, 20, 3, 2009, pp. 329-354,478.

[20] DJ Teece, G. Pisano, and A. Shuen, "Dynamic capabilities and strategic management", Strategic Management Journal, 18, 7, 1997, pp. 509-533.

[21] M. Uhl-Bien, M. Arena, "Complexity leadership: Enabling people and organizations for adaptability", Organizational Dynamics, 46, 2017, pp. 9-20.

[22] M. Basadur, G.Gelade, and T. Basadur, "The Role of Knowledge Management in the Innovation Process", Journal of Creativity and Innovation Management, 15, 1, Wiley Online Library, 2006, pp. 45-62.

[23] I. Nonaka, R. Toyama, and N. Konno, "SECI, Ba and leadership: a unified model of dynamic knowledge creation", Long Range Planning, 33, 2000, pp. 5-34.

[24] E.H. Schein, "Organizational Culture and Leadership", Third Edition, Jossey-Bass, San Francisco, 2004.

[25] K.M. Eisenhardt, "What is the Eisenhardt Method, really?", Strategic Organization, 19, 1, 2021, pp. 147-160.

[26] A. Bryman, "Social Research Methods", Oxford University Press Inc, New York, 2012.

[27] K. Lyytinen, Y. Yoo, and R.J. Boland Jr, "Digital product innovation within four classes of innovation networks", Information Systems Journal, 26, 1, 2016, pp. 47-75.

[28] T. Weiblen and H.W. Chesbrough, "Engaging with Startups to Enhance Corporate Innovation“, California Management Review, 57, 2, 2015, pp. 66-90.

[29] K.M. Eisenhardt and M.E. Graebner, "Theory building from cases: opportunities and challenges", Academy of Management Journal, 50, 1, 2007, pp. 25-32.

[30] A. Dubois and L-E. Gadde, "Systematic combining: an abductive approach to case research", Journal of Business Research, 55, 2002, pp. 553-560.

[31] MD. Myers, "Qualitative Research in Business \& Management", SAGE, second edition, London, 2013.

[32] D. Goncalves, "How Organizational Transparency Strengthens Digital Innovation Capabilities in Startups", In conferencing proceedings Twenty-Ninth European Conference on Information Systems (ECIS 2021), Marrakesh, Morocco, 2021.

[33] Eric Reis, “The Lean Startup, How Today's Entrepreneurs Use Continuous Innovation to Create Radically Successful Business", Random House, first edition, New York, 2011.

[34] K. Schwaber, and M. Beedle, "Agile Software Development with Scrum”, Prentice Hall, New Jersey, 2001.

[35] S. Sarasvathy, "Causation and effectuation: Toward a Theoretical Shift from Economic Inevitability to Entrepreneurial Contingency", Academy of Management Review, 26, 2, 2001,pp. 243-263. 